\title{
Evaluation of microfiber release from jeans: the impact of different washing conditions
}

\author{
Aravin Prince Periyasamy ${ }^{1}$ (D) \\ Received: 4 October 2020 / Accepted: 2 June 2021 / Published online: 11 June 2021 \\ (C) The Author(s) 2021
}

\begin{abstract}
Microplastic particles are a burgeoning population crisis in the marine environment. This research examines the emission of microfibers from three different jeans (garments) during domestic washing. The jeans types, washing temperature, washing duration, spin speed, detergent types, and addition of conditioner are the main factors for this research work. The average length and diameter of the microfibers for the $100 \%$ PET jeans (jeans-P) has $7800 \pm 4000 \mu \mathrm{m}$ and $11.9 \pm 3.2 \mu \mathrm{m}$ and for polyester/cotton jeans (jeans-PB) has $4900 \pm 2200 \mu \mathrm{m} 17.4 \pm 4.8 \mu \mathrm{m}$, respectively. The maximum microfiber released was observed in the rigorous washing treatment $\left(90 \mathrm{~min}, 60^{\circ} \mathrm{C}, 1400 \mathrm{rpm}\right.$, powder detergent with the presence of conditioner). The surmised number of microfibers discharged from the $1 \mathrm{~kg}$ wash load of jeans-P was calculated within the extent of 2300000-4900000 microfibers, and it is varied by the washing treatments.
\end{abstract}

Keywords Microplastics · Microfibers $\cdot$ Jeans $\cdot$ Textiles, Domestic washing

\section{Introduction}

Microplastics have contaminated the environment including water sources such as the ocean and the lakes (Browne et al. 2011; Thompson 2013). Microplastics are synthetic solid particles that have different forms which include microflakes, microbeads, and microfibers (Dervishi 2019). The sources of microfibers in the textile industry are clothing as well as nonclothing applications such as mattresses (Thompson and Olse 2004; Wagner et al. 2014). Generally, these microfibers are observed in both freshwater and marine environment (Neves et al. 2015). It is reported that microplastics are present in the aquatic habitats, beaches, surface waters, and subtidal sediments in a wide range and their abundance is substantially increasing (Thompson and Olse 2004). Barrett et al. (Barrett et al. 2020) estimate at least 14 million tonnes of plastic particles with less than $5 \mathrm{~mm}$ accumulated in the bottom of the ocean. Huge quantities of microplastics were found in nonindustrialized places like Niue, Arutanga, Fiji (Gregory 2009;

Responsible Editor: Philippe Garrigues

Aravin Prince Periyasamy

aravinprince.periyasamy@aalto.fi

1 Textile Chemistry, Department of Bioproducts and Biosystems, Aalto University, Espoo 02150, Finland
Gross 2015). The potential effects in the environment will be influenced by the microplastics which contain two types of chemicals: (i) monomer, polymer, and other additives including colorants and (ii) chemicals absorbed from the surrounding (Campanale et al. 2020). Therefore, it is important to recognize the relative abundance and the sources of various types of microplastics (Koelmans et al. 2013; Bakir et al. 2014). In this work, the shedding of micro-sized fibers from the garments during domestic washing ( 1 to $5 \mathrm{~mm}$ ) is referred to as microfibers. Jeans are the most fashionable and widely used garment (Barajas 2013; Periyasamy et al. 2017) among youngsters. In recent decades, the market potential for jeans has increased tremendously and it is expected to grow by $\$ 3.53$ bn during 2020-2024 (Technavio 2020). Approximately, 1.9 billion pairs of jeans were sold alone in 2015 , which is expected to grow 2.2 billion by 2021 (Technavio 2019). A range of textile fibers was used to produce jeans; polyester (PET) is one among them (Kan et al. 2010, 2011).

Due to the population explosion, the amount of microplastics released to the environment rapidly increases (Ritchie and Roser 2018; Chen et al. 2020; Schernewski et al. 2020). Browne et al. (Browne et al. 2011) studied and suggested that the highest source of microplastic in the form of microfibers is obtained from domestic washing. To evaluate the number of microfiber shedding during domestic washing, various approaches have been developed (Browne et al. 2011; 
Pirc et al. 2016; Napper and Thompson 2016; De Falco et al. 2018b, c, 2019). Particularly, it is observed that the garments made from PET, acrylic, and polyester/cotton at two temperatures $\left(30^{\circ} \mathrm{C}\right.$ and $\left.40^{\circ} \mathrm{C}\right)$ in the presence/absence of a detergent and a fabric conditioner (Napper and Thompson 2016), in this work, a garment made from acrylic emits 728789 microfibers per $6 \mathrm{~kg}$ of garments. Also, $0.0012 \mathrm{wt} \%$ of microfibers are released from PET fleece blankets for each washing process determined by a similar approach (Pirc et al. 2016). In other work (De Falco et al. 2019), the synthetic clothes release which ranges between 124 and $308 \mathrm{mg}$ for $1 \mathrm{~kg}$ of washed clothes vary according to the type of clothes. In other works, the shedding of microfibers released purely depends on the washing conditions, in particular detergents play a vital role (Napper and Thompson 2016; Hernandez et al. 2017; De Falco et al. 2018a). Washing additives like softeners can reduce the microfiber generation up to 35\% (De Falco et al. 2018c). The aged fabrics generally release higher microfibers than the new fabrics (Hartline et al. 2016). Additionally, the number of microfibers released also depends on the washing machines (top-versus and front-load) (Hartline et al. 2016) being utilized, as it is beyond the scope of this study, it and has not been carried out and will be accomplished in near future.

To estimate the real environmental impact of domestic washing of synthetic jeans is essential. It is necessary to identify the parameters which influence the release of microfibers during the washing process. Various works have been published on this topic where the comparisons are not clear due to different methodologies adopted. Most of these works performed on the different synthetic fabrics and their structures (Napper and Thompson 2016; Hartline et al. 2016; Sillanpää and Sainio 2017; De Falco et al. 2018a, 2020; Stanton et al. 2019). To our knowledge, there is no research carried out on the different compositions of jeans with varied washing conditions. An investigative study has been conducted to account the quantity and dimension of microfibers released during washing of three different (i.e., $97 \%$ PET $+3 \%$ elastane; $70 \%$ PET $+27 \%$ cotton $+3 \%$ elastane, and $50 \%$ PET $+50 \%$ cotton) jeans. In this work, the washing treatments are varied such as detergent types, the addition of conditioner, washing temperature $\left(30^{\circ} \mathrm{C}, 45^{\circ} \mathrm{C}\right.$, and $\left.60^{\circ} \mathrm{C}\right)$, washing duration $(60$, 75 , and $90 \mathrm{~min}$ ), and spin speed (1200 and $1400 \mathrm{rpm}$ ). The jeans types, washing temperature, washing duration, spin speed, detergent types, and addition of conditioner are the main factors for this research work since these factors strongly influence the microfiber generations.

\section{Materials and methods}

For this investigation, branded jeans (bottoms) with three different compositions were purchased from fashion outlets in Coimbatore, India. While purchasing, different color of jeans has been chosen to readily differentiate the emitted fibers. The basic properties of three different jeans are given in Table 1 . The detergents (both powder and liquid) and citric acid were purchased from the local shop and Sigma Aldrich India, respectively. The image of washed and unwashed jeans is shown in Figure S1.

\section{Washing process}

For the washing process of jeans, the Whirlpool FRESH CARE has been used. The washing machine is brand new with frontloading technology. There is no other reason for selecting this washing machine rather than the availability as well as the popularity in India. Prior to the garment washing, the machines were cleaned twice by using citric acid with rigorous settings $(120 \mathrm{~min}$,

Table 1 Physical properties of jeans used for this study

\begin{tabular}{|c|c|c|c|c|}
\hline \multicolumn{2}{|l|}{ Composition } & \multirow{2}{*}{$\begin{array}{l}97 \% \text { PET }+3 \% \text { Lycra } \\
\text { jeans-P }\end{array}$} & \multirow{2}{*}{$\begin{array}{l}70 \% \text { PET }+27 \% \text { Cotton }+3 \% \text { Lycra } \\
\text { jeans-PA }\end{array}$} & \multirow{2}{*}{$\begin{array}{l}50 \% \text { PET }+50 \% \text { cotton } \\
\text { jeans-PB }\end{array}$} \\
\hline Abbreviation & & & & \\
\hline \multirow[t]{2}{*}{ Cover factor (Yarns/inch) } & warp & 81 & 83 & 84 \\
\hline & weft & 51 & 51 & 49 \\
\hline \multirow[t]{2}{*}{ Hairiness index } & warp & 4.3 & 3.8 & 3.8 \\
\hline & weft & 4.3 & 3.8 & 3.8 \\
\hline Staple fiber length (mm) & & 38 & 32 & 32 \\
\hline \multirow[t]{2}{*}{ Linear density (tex) } & warp & $59 / 1$ & $59 / 1$ & $60 / 1$ \\
\hline & weft & $36.8 / 1$ & $42 / 1$ & $40 / 1$ \\
\hline \multicolumn{2}{|l|}{ Construction } & $3 \times 1$ RHT & $3 \times 1$ RHT & $3 \times 1 \mathrm{RHT}$ \\
\hline \multicolumn{2}{|l|}{ Style } & Women's bottom & Women's bottom & Women's bottom \\
\hline \multirow{2}{*}{\multicolumn{2}{|c|}{ Color }} & Blue & Light blue & Navy \\
\hline & & 453 & 457 & 462 \\
\hline
\end{tabular}

Note: RHT right-hand twill 
$60^{\circ} \mathrm{C}, 1400 \mathrm{rpm}$ ). A single garment (jeans) was washed separately and dried in atmospheric conditions (i.e., line dry); later, the garments were worn to simulate the real wash (i.e., home laundering) and wear conditions. The washing was carried out by implementing six levels $(\mathrm{A}-\mathrm{F})$ of detergent/conditioner treatments $\times$ washing duration with three levels $(60,75,90 \mathrm{~min}) \times$ washing temperature with three levels $\left(30,45,60^{\circ} \mathrm{C}\right) \times$ spin speed with two levels (1200, $1400 \mathrm{rpm})$, and thus, there were $108(6 \times 3 \times 3 \times 2=108)$ experiments. To reduce the statistical error, after wearing, each garment was washed four times (i.e., replicates) separately according to the specific washing conditions (i.e., $108 \times 4=432$ ), for all the jeans used for this work (jeans-P, jeans-PA, and jeans-PB). The detailed information on the washing conditions is given in Table 2 . The quantity of conditioner and detergents had been kept constant throughout the cycles with the same volume of water $(15 \mathrm{~L})$. This research is to investigate the microfibers released in the washing machine which does not contain the tumble dryer since such machines are expensive and not commonly used in India. Usage of a tumble dryer after washing is beyond the scope of this present study. The inclusion and exclusion criteria for washings were provided in Table S1 and the composition of different detergents is given in Table S2.

\section{Filtration, removal, and counting of the microfibers}

The total quantity of washing effluent was collected from the washing machine after the washing process of single jeans. The residual microfibers were collected by filtering the wastewater in the external filters including stainless steel $(200 \times 200 \mu \mathrm{m})$, and PTFE $(5 \mu \mathrm{m})$ was fixed at the end of the drain hose. Once the washing is completed, the filter was removed carefully, dried in atmospheric condition. While drying, both filters were covered by aluminum foil to avoid airborne. Later, the microfibers were collected cautiously to weigh it from both stainless steel and PTFE filter. The emitted microfibers per jeans are calculated based on the following equation (Napper and Thompson 2016; De Falco et al. 2018b).
$T=\left(\frac{4 A_{M P}}{\pi D^{2} l \rho}\right)$

where $T$ is the total number of microfibers per jeans, and $A_{M P}$ is the total mass of microfibers collected from both filters. Assuming that the collected fibers were cylindrical structure, (Napper and Thompson 2016), $D$ and $l$ are the average diameter and length of extracted fibers, $\rho$ is the density of the material (for PET-1.38 g/ $\mathrm{cm}^{3}$, for lycra $1.25 \mathrm{~g} / \mathrm{cm}^{3}$, and cotton is 1.540 $\left.\mathrm{g} / \mathrm{cm}^{3}\right)$.

\section{Characterization}

After drying, the microfibers were carried out to analyze the surface morphology. Both, scanning electron microscope (SEM) and the optical microscope were used for the surface analysis. TS5130 Vega-Tescan SEM (Czech Republic) was used with the following conditions: $20 \mathrm{kV}$ accelerating voltage and $\times 500$ with a vacuum of $7.8 \times 10^{-3} \mathrm{~Pa}$. OLYMPUS SZ61 optical microscope was used for the complement micrographs on the microfibers to evaluate the length and diameters of the fibers. Later, the SEM images were analyzed by using public domain software ImageJ in order to measure the length and diameter of the microfibers collected from both the filters; it can be repeated 40 times to reduce the statistical error, and the mean values are used for further calculations. The working distance between the sample and the objective lens can be adjusted according to the image resolution. For the confirmation of residual fibers' chemistry, the Fourier transform infrared spectroscopy (FTIR-ATR) was used before and after the washing process. Statistical analysis was conducted using IBM SPSS 26 (IBM, Inc., Armonk, NY, USA). A 5-way analysis of variance (ANOVA) was analyzed between the jeans types, different washing treatments, spin speed, washing duration, and washing temperature. The criterion for statistical significance was set as 0.05 .

Table 2 Detailed information on the washing conditions uses for this work

\begin{tabular}{|c|c|c|c|c|c|c|c|c|c|}
\hline \multirow{2}{*}{$\begin{array}{l}\text { Abbreviation (six levels) } \\
\text { A }\end{array}$} & \multirow{2}{*}{$\begin{array}{l}\text { Washing dose (for } 15 \mathrm{~L} \text { water) } \\
\text { No detergent + no conditioner }\end{array}$} & \multicolumn{3}{|c|}{ Washing duration (min) } & \multicolumn{3}{|c|}{ Washing temperature $\left({ }^{\circ} \mathrm{C}\right)$} & \multicolumn{2}{|c|}{ Spin speed (rpm) } \\
\hline & & 60 & 75 & 90 & 30 & 45 & 60 & 1200 & 1400 \\
\hline B & No detergent + conditioner $(40 \mathrm{~mL})$ & 60 & 75 & 90 & 30 & 45 & 60 & 1200 & 1400 \\
\hline $\mathrm{C}$ & Liquid detergent $(60 \mathrm{~mL})+$ no conditioner & 60 & 75 & 90 & 30 & 45 & 60 & 1200 & 1400 \\
\hline $\mathrm{D}$ & Liquid detergent $(60 \mathrm{~mL})+$ conditioner $(40 \mathrm{~mL})$ & 60 & 75 & 90 & 30 & 45 & 60 & 1200 & 1400 \\
\hline $\mathrm{E}$ & Powder detergent $(65 \mathrm{~g})+$ no conditioner & 60 & 75 & 90 & 30 & 45 & 60 & 1200 & 1400 \\
\hline $\mathrm{F}$ & Powder detergent $(65 \mathrm{~g})+$ conditioner $(40 \mathrm{~mL})$ & 60 & 75 & 90 & 30 & 45 & 60 & 1200 & 1400 \\
\hline
\end{tabular}




\section{Results and Discussions}

\section{Characterization of microfibers}

The morphological analysis for the microfibers collected from the washing effluent has been analyzed, and the images are shown in Fig. 1. From this image, it is evidenced that several fibers show the surface damage or ripped-off from the fiber structure (Fig. 1b, j); also, there is a fracturing of the fiber in a few situations (Fig. 1h). However, a few fiber fragments show surface damages due to the washing actions (Fig. 1b, c, e, and $\mathrm{f}$ ). This is due to the consequence of mechanical stress suffered by the jeans garment throughout the washing process. Besides, the detachment of microfibers was observed as it is clearly shown in Fig. 1e, i, and j. Further, SEM images were used to calculate the average length of collected microfibers from the washing effluent. In some cases, it is very difficult to measure, due to the entanglement of fibers in which some are strongly bound together (i.e., in particular, the microfibers collected from higher spin speed and higher washing temperature). Therefore, the average length of the microfibers estimation was under-estimated. However, the measurement takes 40 different locations of fibers to calculate the average length and diameter. The average length and diameter of the microfibers released from different types of jeans were tabulated in Table 3.

\section{ATR-FTIR spectra for microfibers}

To evaluate the chemistry of microfibers collected after the washing process, ATR-FTIR spectroscopy was utilized to characterize the functional groups with the resolution of wavenumber range from 400 to $4000 \mathrm{~cm}^{-1}$. The spectra for jeans (before washings) and released microfibers (after washings) can be compared and concluded with the help of the Institute of chemical University of Tartu, Estonia (Peets et al. 2017) guidelines. Both before and after washings were observed with similar peaks for all the types of jeans (i.e., jeans-P, jeans-PA, and jeans-PB). A detailed description of the observed peaks was given in Figure S2.

\section{Domestic washing and microfibers emission}

The quantity of microfibers released is determined and plotted in Figs. 3, 4, and 5.
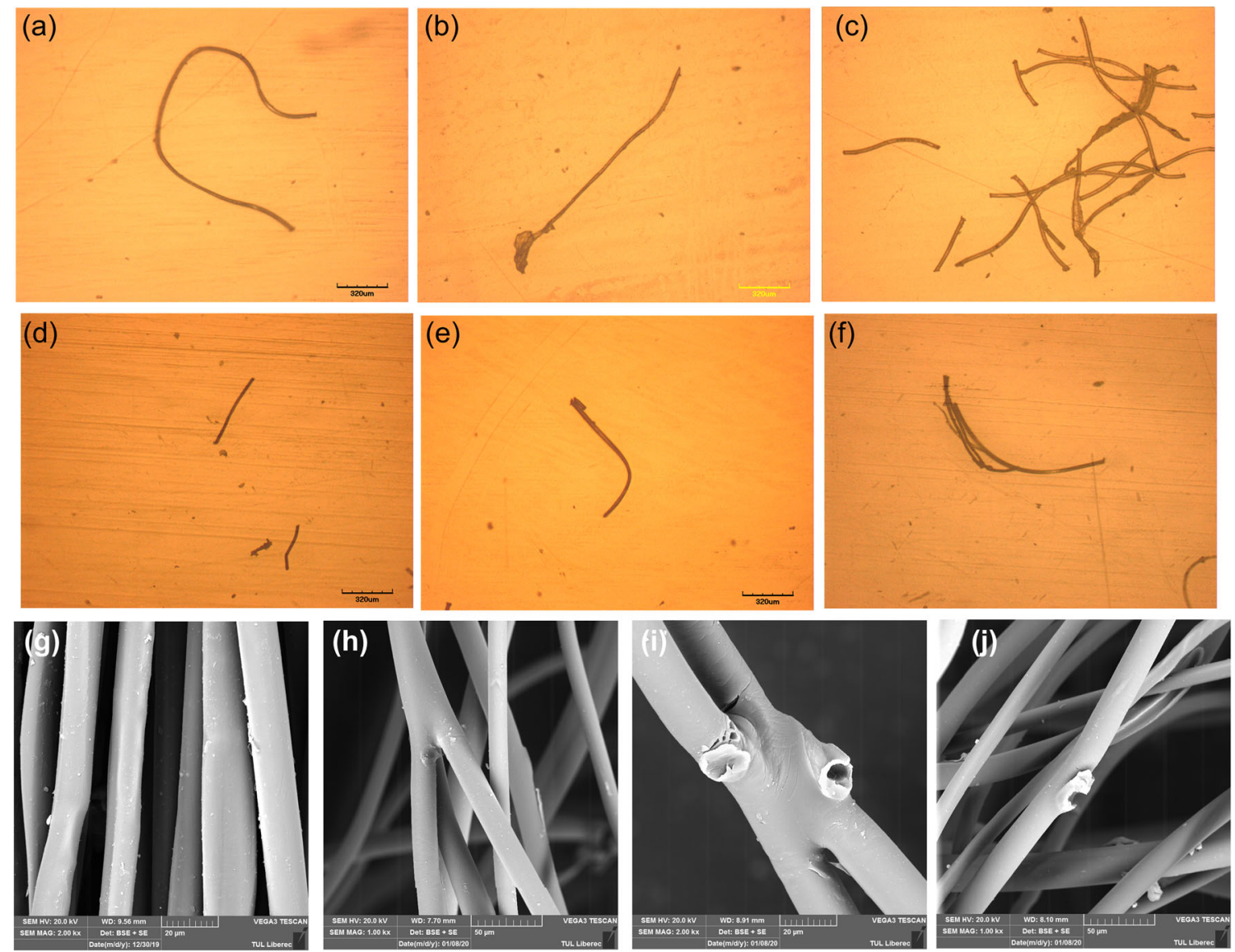

Fig. 1 Optical microscopy images $(\times 100)$ of representative fibers collected on the $5 \mu \mathrm{m}$ PTFE filter, jeans-P $(\mathbf{a}-\mathbf{c})$; jeans-PB $(\mathbf{d}-\mathbf{f})$; SEM images of jeans$\mathrm{P}$ unwashed (g); washed $(\mathbf{h}-\mathbf{j})$ 
Table 3 Details of microfiber generations in different jeans

\begin{tabular}{llll}
\hline Factors & jeans-P & jeans-PA & jeans-PB \\
\hline Length $(\mu \mathrm{m})$ & $7800 \pm 4000$ & $6660 \pm 4000$ & $4900 \pm 2200$ \\
Diameter $(\mu \mathrm{m})$ & $11.9 \pm 3.2$ & $12.6 \pm 4.2$ & $17.4 \pm 4.8$ \\
Microfiber releases per kg of jeans & $2305395-4874323$ & $619581-1085431$ & $561683-865182$ \\
\hline
\end{tabular}

\section{Impact on washing Temperature}

In the jeans-P, maintaining the constant washing treatment "C," 2877278, 3121692, and 3283341 of microfibers were released varying with the washing temperature from $30^{\circ} \mathrm{C}$, $45^{\circ} \mathrm{C}$, and $60^{\circ} \mathrm{C}$, respectively (Fig. 2); the observed trend is similar for all washing treatments. Temperature is directly proportional to the release of microfibers which is depicted in (Figs 2, 3, and 4). By maintaining the temperature constant, $6.9 \%, 21.4 \%, 21.4 \%, 24.8 \%$, and $35 \%$ of microfibers are recorded with the washing treatments of B, C, D, E, and F, respectively (Fig. 2d). The release of microfiber increases with the increasing washing temperature irrespective of the fabric used. Evidence shows that the possibility of jeans-P to release higher microfibers during washing with high temperature is due to the surface hydrolysis characteristic of polyester under alkaline medium (i.e., powder detergent). On the other hand, temperature increases the swelling action of the cellulose portion in the jeans under alkaline condition and also increases (Duckworth and Wrennall 1977; Nishimura and Sarko 1987) the fuzz formation. The hydrogen bonds between the cellulose chains are disrupted when the detergent mixed with water pierced into the amorphous regions of the cellulose fibers resulting in the fiber swelling. Henceforth, the cellulosic fibers swell as the temperature increases consequently creating free space in the textile structure for the mobilization of the broken fibers. Fuzz formation on the surface of swollen fibers is increased due to the mechanical actions in the washing process (Fig. 6). It further increases with increasing the washing temperature, spin speed, and duration.

\section{Impact of washing detergent}

When the garments are washed using a surfactant which creates the foam, it results in a reduction of mechanical agitation during the washing process (Coons et al. 1987; Bishop 1995; Sommer 2001). Yet, similar results were not observed in our experiment as the release of microfibers is higher by adding the detergent as well as conditioner. Our investigation emphasizes the results that the microfibers are abundant due to the addition of detergents. Washing treatment " $B$ " for jeans-P releases (i.e., spin-speed of $1200 \mathrm{rpm}, 30^{\circ} \mathrm{C}$ with $75 \mathrm{~min}$ ) $6.85 \%, 21.8 \%, 23.7 \%, 31.3 \%$, and $36.4 \%$ higher microfibers on the treatments of B, C, D, E, and F, respectively (Fig. 2b) as compared to the washing treatment "A." There is a similar trend observed in Figs. 3b (jeans-PA) and 4b (jeans-PB). The release of microfibers is higher when powder detergent (i.e., washing treatment "E") was used; this is due to the alkalinity of detergent (i.e., the $\mathrm{pH}$ of powder and liquid detergent is 10.6 and 9.1, respectively) as well as the presence of inorganic compounds ( $\mathrm{TiO}_{2}$ dyes). The alkaline nature of the powder detergent causes surface hydrolysis of jeans-P when exposed to higher washing temperatures and washing time. Powder detergent also induces chemical damage to the jeans which is exposed to the extended washing time. The hydrolysis of PET fibers takes place when the PET undergoes a hot alkaline environment, which causes the nucleophilic substitution reaction on hydroxyl ion which attacks the carboxyl carbon of PET following the chain scission resulting in the production of hydroxyl and carboxylate end groups (Dave et al. 1987; Zeronian and Collins 1989). Additionally, the friction between the jeans and machine drum increases due to the inorganic compounds present in the powder detergent. Apart from that, poor alkali fastness of indigo dye-fiber bonds (Chakraborty 2014; Sarkar 2015), resulting in the bond breakage and releasing microfibers in jeans-PA and jeans-PB. Both the liquid and powder detergent induce the increase of microfiber releases which is based on these results as compared to the washing treatment "A." That is the reason why the powder detergent has a strong influence on the shedding of microfibers from all types of jeans during the washing (Figs. 2, 3, and 4). In this study, the surface of the filter shows no accumulation or thick layer formation as the detergent dissolved completely as found in the De Falco et al. (De Falco et al. 2018c) works.

\section{Effect of conditioner, spin speed, and washing duration}

There were additionally some noteworthy impacts of conditioner use, where all jeans reliably shed more microfibers when conditioner was used as compared to the detergent. In the washing treatment ' $\mathrm{A}$ ' (i.e. spin-speed- $1200 \mathrm{rpm}, 30^{\circ} \mathrm{C}$, $60 \mathrm{~min}$ ) releases $2305395 \pm 115269$ microfibers per $\mathrm{kg}$ of jeans-P (Figure 2-a), (whereas jeans-PA- $619581 \pm 30979$ and jeans-PB $561683 \pm 28084)$, whereas with the addition of conditioner $2469868 \pm 123493$, (for jeans-PA- $624039 \pm$ 31201 (Figure 3-a) and jeans-PB $561683 \pm 28084$ (Figures 4-a and S3)). The presence of detergent and the conditioner play a vital role; it increases the microfiber shedding for jeans-P from 2877278 to 2982681 (i.e., washing treatment 

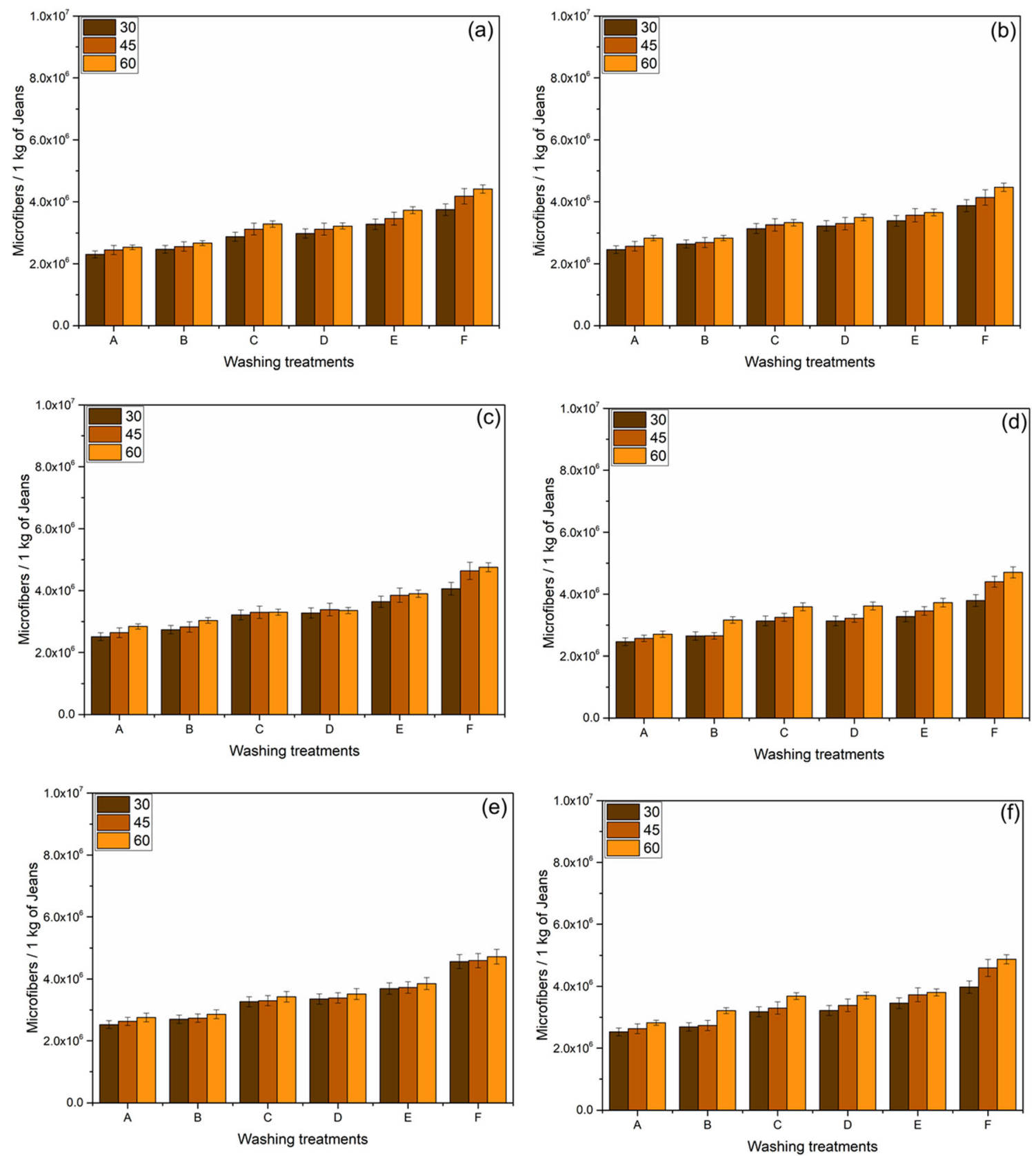

Fig. 2 An average relative of microfibers released during successive washing of jeans-P, 60 min washing time spin speed $1200 \mathrm{rpm}(\mathbf{a})$; 75 min washing time spin speed $1200 \mathrm{rpm}$ (b); 90 min washing time

spin speed $1200 \mathrm{rpm}$ (c); 60 min washing time spin speed $1400 \mathrm{rpm}$ (d); 75 min washing time spin-speed $1400 \mathrm{rpm}$ (e); and 90 mins washing time spin speed $1400 \mathrm{rpm}$ (f) (error bars represent standard deviation)

C to D) for liquid detergent and 3275154 to 3743691 (i.e., washing treatment $\mathrm{E}$ to $\mathrm{F}$ ) for powder detergent ((Fig. 2a). This trend is almost the same for jeans-PA (Fig. 3a) and jeans-PB (Fig. 4a). Generally, the microfiber releases are the same with washing treatment " $\mathrm{C}$ " which linearly increases when increasing the washing durations (Figure. S4). For three jeans, the influence of spin speed with different washing was plotted in Fig. 5. Likewise, the washing duration and the spin speed are directly proportional to the microfiber shedding.
This is due to the higher beating and rubbing (friction) action during the washing process. The observed trend is similar for jeans-P (Fig. 5a), jeans-PA (Fig. 5b), and jeans-PB (Fig. 5c). Other than that, it is important to note that the conditioner does not have enough softener content (i.e., hand feel on the jeans after washing); usually, the higher softener content reduces the friction between the machine action and garments during the washing process. In our case, the conditioner manufacturer did not provide the ratio of the chemical composition of the 

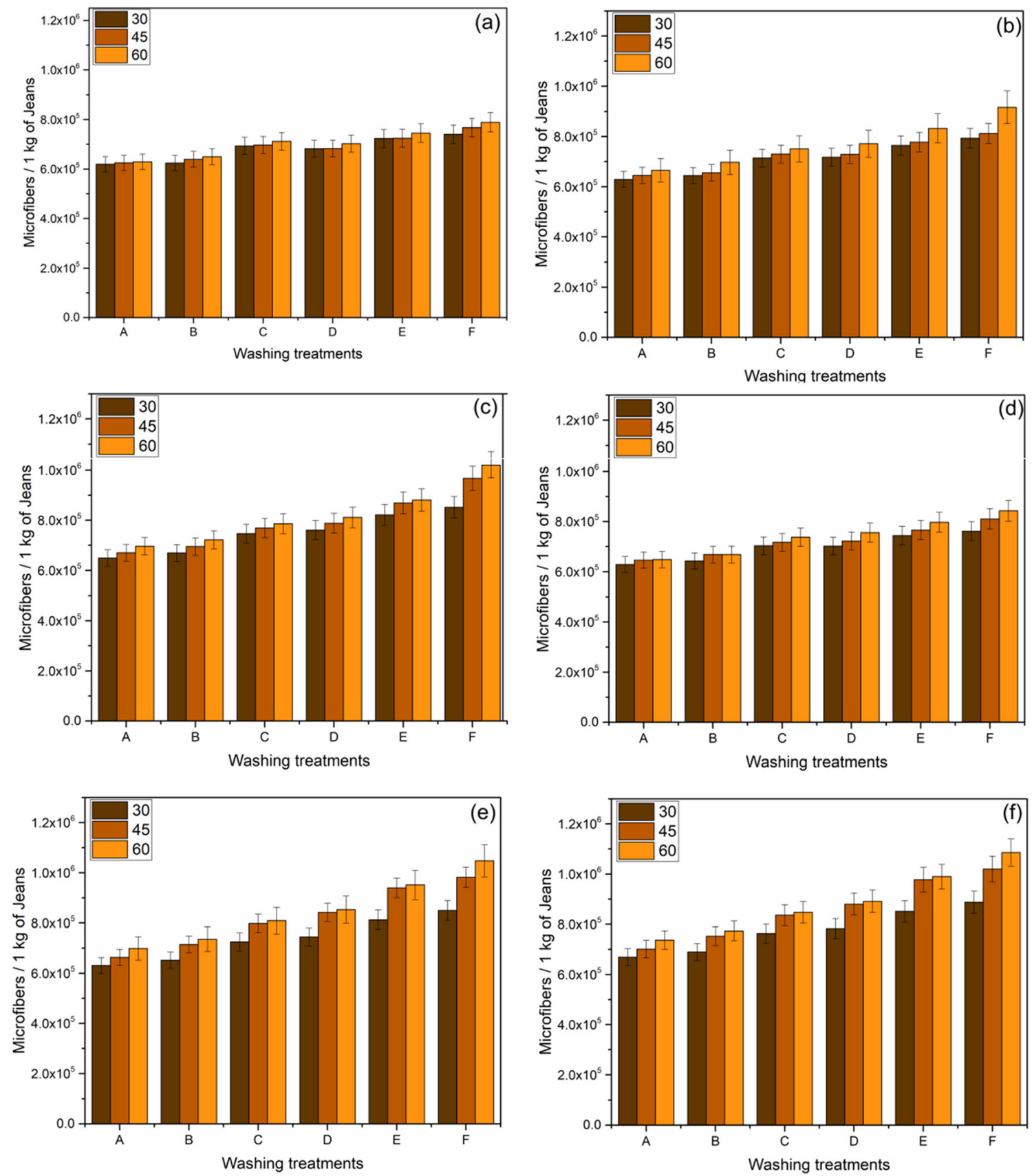

Fig. 3 An average relative of microfibers released during successive washing of jeans-PA, 60 min washing time spin speed $1200 \mathrm{rpm}$ (a); 75 min washing time spin speed $1200 \mathrm{rpm}$ (b); 90 min washing time spin speed $1200 \mathrm{rpm}(\mathbf{c}) ; 60 \mathrm{~min}$ washing time spin speed $1400 \mathrm{rpm}$

conditioner due to the copyrights and patent. Henceforth, further discussion is not feasible. In jeans-PB, there is $27.5 \%$ of microfiber shedding when the temperature increased from 30 to $60^{\circ} \mathrm{C}$ (Fig. $4 \mathrm{c}$ ). Additionally, the study nourishes the fact that microfiber emission is influenced by the spin speed. When the spin speed of $1400 \mathrm{rpm}$ with an increase of duration to $90 \mathrm{~min}$ shows the rigorous level of microfiber releases, it can be seen in Fig. 2d and e, respectively, for jeans-P and Fig. $4 \mathrm{~d}$ and e for jeans-PB.

(d); 75 min washing time spin speed $1400 \mathrm{rpm}$ (e); and $90 \mathrm{mins}$ washing time spin speed $1400 \mathrm{rpm}$ (f) (error bars represent standard deviation)

\section{Yarn and Fabric characteristics}

Generally, the fabric types (i.e., weave structure and designs) and yarn types (i.e., filament or staple yarns) have a significant influence on the releasing of microfibers during the washing process. Nevertheless, fabrics made from $100 \%$ synthetic or synthetic blends release higher microfibers as compared to the natural fibers (Pirc et al. 2016; Napper and Thompson 2016; Sillanpää and Sainio 2017) since our results also confirm it. 

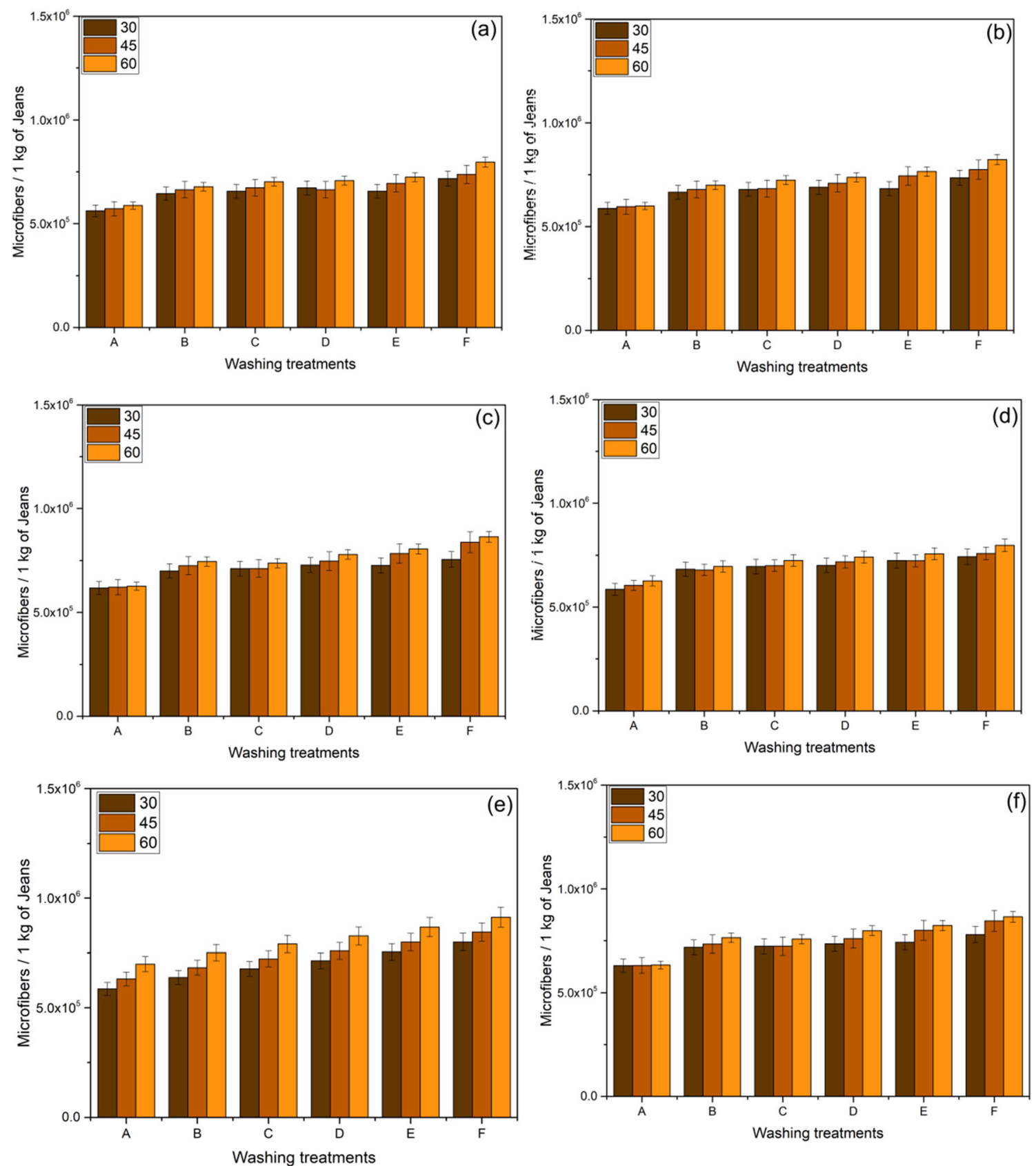

Fig. 4 An average relative of microfibers released during successive washing of jeans-PB, 60 min washing time spin speed $1200 \mathrm{rpm}(\mathbf{a})$; $75 \mathrm{~min}$ washing time spin speed $1200 \mathrm{rpm}$ (b); 90 min washing time

spin speed $1200 \mathrm{rpm}$ (c); 60 min washing time spin speed $1400 \mathrm{rpm}$ (d); 75 min washing time spin speed $1400 \mathrm{rpm}$ (e); and 90 min washing time spin speed $1400 \mathrm{rpm}$ (f) (error bars represent standard deviation)

Moreover, the release of microfibers mostly depends on their blend proportion (Napper and Thompson 2016; Zambrano et al. 2019). The results from the previous works (Napper and Thompson 2016) are more generalized with the microfiber generations and their blend proportion ratio. However, it cannot generalize the releases of microfibers from the fabric made from different blend proportions or $100 \%$ synthetic fabric. Yet the following factors such as filament or short-staple fiber, staple length, yarns twist per inch, type of spinning (i.e., open-end, ring spinning), type of yarn (i.e., combed yarn, carded yarn), weave structure, fabric porosity, fabric density (i.e., both warp and weft density), singeing process, number of wet processes, weaving speed, etc. play a vital role in the generation of microfibers. The release of microfiber is higher when the protruding fibers (i.e., due to yarn hairiness) are present in the fabric surface, which is further possible to form 

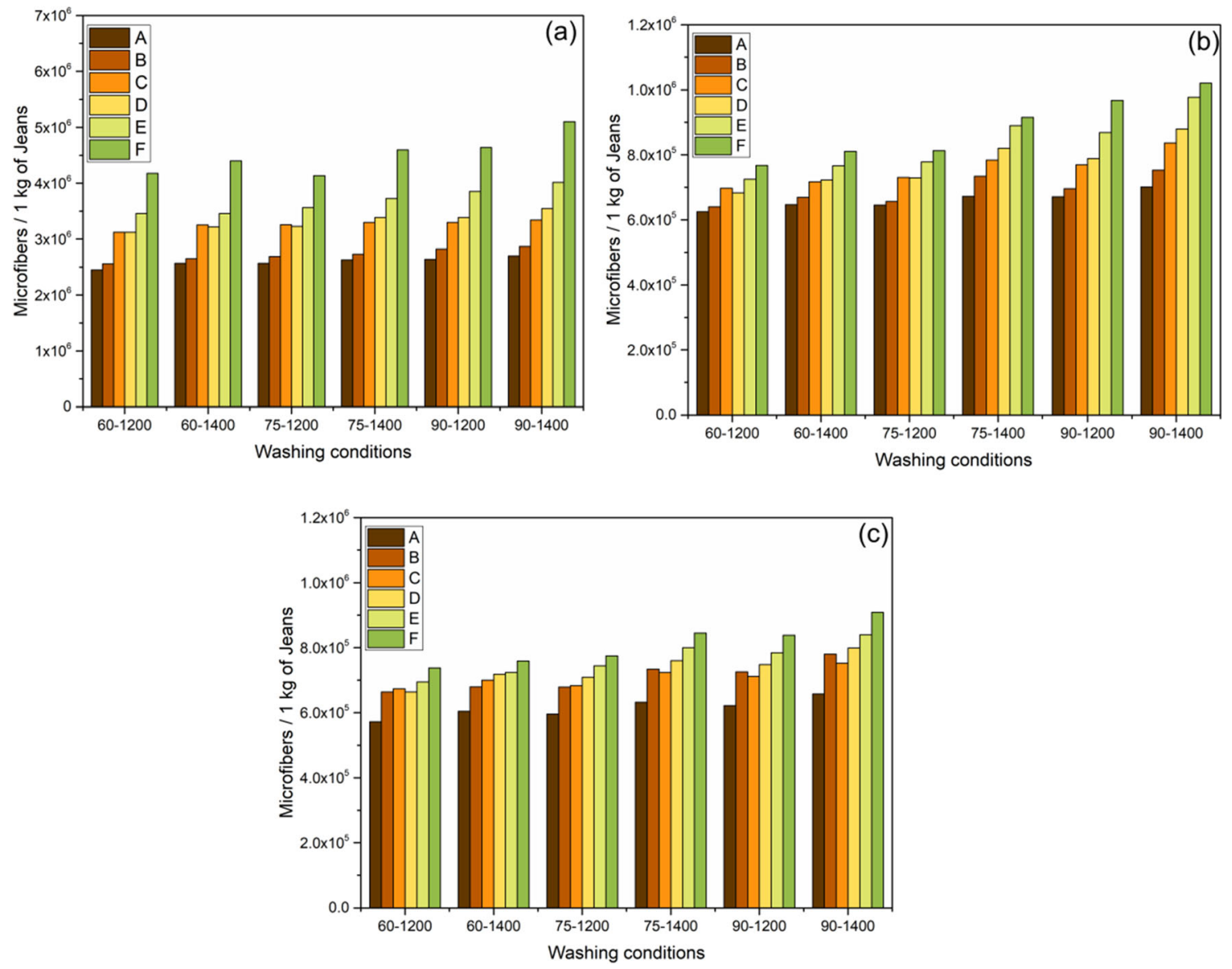

Fig. 5 Influence of spin speed and washing duration on microfiber emission, jeans-P $(\mathbf{a})$; jeans-PA $(\mathbf{b})$; and jeans-PB (c) (i.e., washing temperature $\left.45^{\circ} \mathrm{C}\right)$

the fuzz (Ratnam 2010). The tendency of pilling is initiated from the fuzz formation (Periyasamy 2020) which detaches during the washing process in the machine due to their mechanical action. As per the reference (Chiweshe and Crews 2000), the fabric conditioners increase the possibilities of pilling generations on synthetic fabrics. The pill formation delivers a similar mechanism for both synthetic fibers like polyester and cellulosic fibers like cotton/lyocell; the predicted mechanism for the microfiber generations is shown in Fig. 6. The formation of microfiber and the release is mainly due to the surface rupture of staple fibers under mechanical actions.

In this study, both the warp (doubled) and weft (doubled) for jeans-PA and jeans-PB have the same hairiness index (i.e., Uster hairiness index 3.8 , for jeans-P is 4.3 ) as provided by the producer. The jeans-P has a higher hairiness index than the jeans-PA/jeans-PB (i.e., according to SITRA norms (Ratnam 2010)), which is another reason for the shedding of higher microfibers during the washing. Since hairiness plays a vigorous role (Ratnam 2010); however, it cannot be generalized. In general, hairiness is mostly observed in the yarn made from staple fibers, since the higher cut length may have possibilities of lower hairiness and vice versa.
Frequently, the lengths of staple fiber are usually cut higher than $32 \mathrm{~mm}$ either for synthetic or regenerated fibers (Mcloughlin and Hayes 2013). Fiber length is one of the important parameters on the microfiber generations; the longer yarns have the least possibilities of slip from the yarn structure. Microfiber release also depends on other factors such as fabric weight. In general, heavier fabric releases more count of microfibers than lighter fabrics. When the yarn is twisted higher the slipping of fibers from the yarn structure is less which reduces the microfiber releases following Almroth et al. (Carney Almroth et al. 2018). Particularly, garments made out of highly twisted continuous filaments with low hairiness tend to release fewer microfibers during the washing. Generally, the fabric with higher work of rupture (i.e., resistance towards the abrasion), tensile strength, and low hairiness value shows to be the lowest to possibly form fuzz/fibrillation which further breaks and emits from the fabric that is called microfibers.

The 5-way ANOVA was conducted to know the significant complex interaction between five independent variables (jeans types, washing treatment levels (A-F), washing temperature, spin speed, and washing duration); the 


\section{Denim fabric}
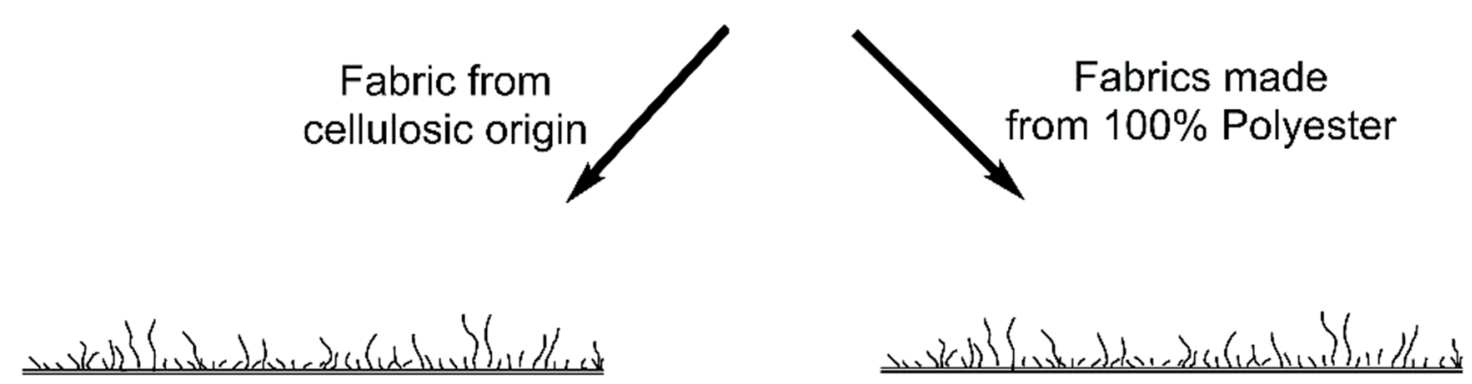

Fuzz formation due to wearing and washing

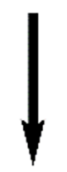

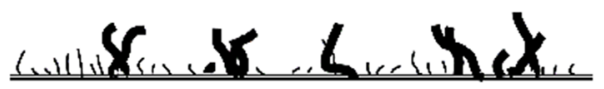

Swelling (water / alkaline condition)
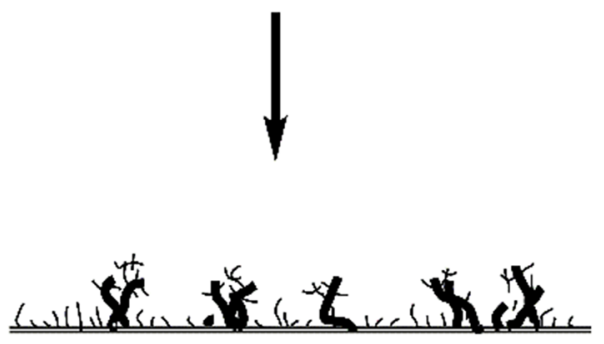

Fibrillation formation

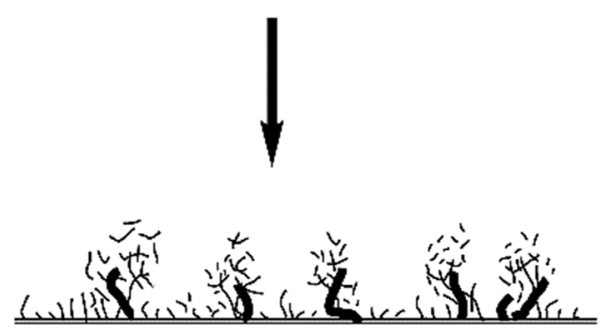

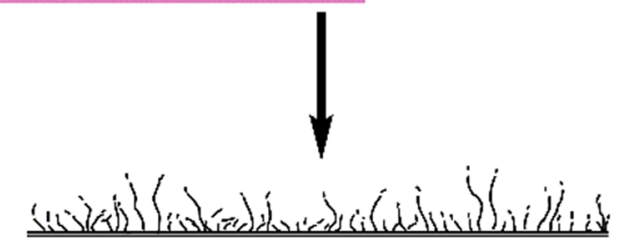

Surface hydrolysis (higher temperature / alkaline condition)

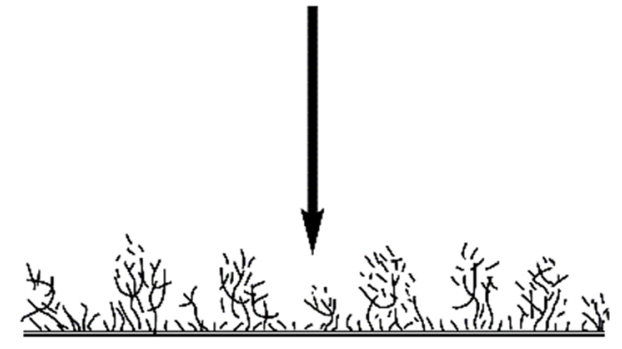

Fiber breaking

\section{Fiber breaking}

Fig. 6 A proposed mechanism of microfiber generation on jeans made from PET and cellulosic fibers (Adapted and modified from (Periyasamy 2020))

results are given in Table 4. The possible interaction between the variables is taken into account. The main effects of each variable were consistently significant indicating the variance in microfiber emissions. The interaction effect between the variables (Washing duration * spin speed * washing treatments $*$ washing temperature * jeans types) was significant implying that there is an effect of variables influencing the shedding of microfibers. There is no significant interaction between washing duration * spin speed * washing treatments * washing temperature and spin speed * washing treatments * washing temperature * jeans types. Hence, the highest microfibers were released under washing treatment "F," $1400 \mathrm{rpm}, 90 \mathrm{~min}$, and $60^{\circ} \mathrm{C}$. A list of previous works was summarized in Table S3. For better comparison, our results have been converted according to the previous works. Table S3 shows the perfect comparison of the mass of jeans (garments) rather than the volume of garments. Overall, the comparison states that the number of microfibers released on our results is higher than the previous results. 
Table 4 Analysis of variance (ANOVA) for factors influencing the shedding of microfibers (Duration, washing duration; speed, spin speed; Temp, washing temperature; and fab, jeans types)

\begin{tabular}{|c|c|c|c|c|c|}
\hline Source & Type III sum of squares & df & Mean square & $\mathrm{F}$ & Sig. \\
\hline Corrected model & $525407692641103.2^{\mathrm{a}}$ & 275 & 1910573427785 & 531.987 & .000 \\
\hline Intercept & 832817750114045 & 1 & 832817750114045 & 231893.7 & .000 \\
\hline Duration $(60,75$, and $90 \mathrm{~min})$ & 780033260034.01 & 2 & 390016630017 & 108.5 & .000 \\
\hline Speed (1200 and $1400 \mathrm{rpm})$ & 310658235934.9 & 1 & 310658235934.9 & 86.5 & .000 \\
\hline Washing treatments (A-F) & 18238594586469.9 & 5 & 3647718917293.9 & 1015.6 & .000 \\
\hline Temp $\left(30^{\circ} \mathrm{C}, 45^{\circ} \mathrm{C}\right.$, and $\left.60^{\circ} \mathrm{C}\right)$ & 1460583690768.2 & 2 & 730291845384.1 & 203.3 & .000 \\
\hline Fab (jeans-P, jeans-PA, and jeans-PB) & 482541916568759 & 2 & 241270958284379 & 67180.6 & .000 \\
\hline Washing treatments $*$ fab & 19153221115388.4 & 10 & 1915322111538.8 & 533.311 & .000 \\
\hline Speed $*$ washing treatments & 49110020083.1 & 5 & 9822004016.6 & 2.735 & .030 \\
\hline Washing treatments $*$ temp & 239735000390.4 & 10 & 23973500039 & 6.675 & .000 \\
\hline Duration $*$ washing treatments & 95802979982 & 10 & 9580297998.2 & 2.668 & .011 \\
\hline Speed $*$ washing treatments $*$ fab & 169956238685.1 & 12 & 14163019890.4 & 3.944 & .000 \\
\hline Washing treatments $*$ temp $*$ fab & 1318040351635.4 & 12 & 54918347984.8 & 15.2 & .000 \\
\hline Duration $*$ washing treatments $*$ fab & 228483146982.7 & 24 & 9520131124.2 & 2.6 & .002 \\
\hline Speed $*$ washing treatments $*$ temp & 51635799971.8 & 12 & 4302983330.9 & 1.19 & .312 \\
\hline Duration $*$ speed $*$ washing treatments & 148150835645.3 & 12 & 12345902970.4 & 3.43 & .001 \\
\hline Duration $*$ washing treatments $*$ temp & 87219439823.5 & 12 & 3634143325.9 & 1.01 & .471 \\
\hline Speed $*$ washing treatments $*$ temp $*$ fab & 74705070288.9 & 24 & 3112711262 & .867 & 640 \\
\hline Duration $*$ speed $*$ washing treatments $*$ fab & 176525950365.8 & 24 & 7355247931.9 & 2.048 & .017 \\
\hline Duration $*$ washing treatments $*$ temp $*$ fab & 218677099466.7 & 48 & 4555772905.5 & 1.269 & .206 \\
\hline Duration $*$ speed $*$ washing treatments $*$ temp & 64643250429.6 & 24 & 2693468767.9 & .750 & .775 \\
\hline Duration $*$ speed $*$ washing treatments $*$ temp $*$ fab & 1823859458646 & 48 & 390016634455 & .685 & .412 \\
\hline Error & 172386105304.8 & 24 & 3591377193.8 & & \\
\hline Total & 1358397828860285 & 324 & & & \\
\hline Corrected Total & 525580078746408 & 323 & & & \\
\hline
\end{tabular}

a. R Squared $=1.000$ (Adjusted R Squared $=.998)$

\section{Conclusion}

The current study aimed to quantify the microfiber emission during domestic washing of jeans with varied washing conditions. From this work, it is concluded that the jeans types, washing temperature, washing duration, spin speed, detergent types, and addition of conditioner strongly influence the microfiber generations. When washing undergoes domestic treatments, the results show that jeans-P releases the highest number of microfibers concerning jeans-PA and jeans-PB. Further trials confirmed that the powder detergent sources are higher than the generation of microfibers as compared to liquid detergent. The approximate number of microfibers released from a typical $1 \mathrm{~kg}$ wash load of jeans-P was calculated in the range of 2305395-4874323.3 (for jeans-PA 619581.31085431.3 and 561683.2-865182.1 for jeans-PB) as it is influenced by the washing treatments. There was a consistent trend between the jeans types. A 5-way analysis of variance (ANAVO) reveals significant interactions between 5 variables. To prevent microfiber pollution, it is essential to consider the factors in the calculation of risk reduction interventions. Henceforth, it is mandatory to extend this work to have detailed data regarding the types of washing machines, age of jeans, and fabric weave structure; however, be beneficial. Microfiber generations are also influenced by the physical and chemical properties of fibers, yarn, and fabric apart from the washing treatments. Hence, this investigation refurbishes the jeans industry to contribute less microfiber emission.

Supplementary Information The online version contains supplementary material available at https://doi.org/10.1007/s11356-021-14761-1.

Acknowledgement The author thanks to Technical University of Liberec, Czech Republic for providing the facilities to carrying out the SEM images.

Availability of data and materials The datasets generated and/or analyzed during the current study are not publicly available due to legal and commercial restrictions but are available from the corresponding author on reasonable request. 
Author contribution Conceptualization, methodology, formal analysis and investigation, writing original draft preparation, and writing review and editing: APP.

Funding Open access funding provided by Aalto University.

\section{Declarations}

Ethics approval and consent to participate Not applicable.

Consent for publication Not applicable.

Competing interests The author declares no competing interests.

Open Access This article is licensed under a Creative Commons Attribution 4.0 International License, which permits use, sharing, adaptation, distribution and reproduction in any medium or format, as long as you give appropriate credit to the original author(s) and the source, provide a link to the Creative Commons licence, and indicate if changes were made. The images or other third party material in this article are included in the article's Creative Commons licence, unless indicated otherwise in a credit line to the material. If material is not included in the article's Creative Commons licence and your intended use is not permitted by statutory regulation or exceeds the permitted use, you will need to obtain permission directly from the copyright holder. To view a copy of this licence, visit http://creativecommons.org/licenses/by/4.0/.

\section{References}

Bakir A, Rowland SJ, Thompson RC (2014) Enhanced desorption of persistent organic pollutants from microplastics under simulated physiological conditions. Environ Pollut 185:16-23. https://doi. org/10.1016/j.envpol.2013.10.007

Barajas E (2013) In with the old, in with the new consumers embrace denim's innovation and heritage. Cott. lifestyle, In https:// lifestylemonitor.cottoninc.com/in-with-the-old-in-with-the-new/. Accessed 2 Mar 2021

Barrett J, Chase Z, Zhang J, Holl MMB, Willis K, Williams A, Hardesty BD, Wilcox C (2020) Microplastic Pollution in Deep-Sea Sediments From the Great Australian Bight. Front Mar Sci 7. https://doi.org/10. 3389/fmars.2020.576170

Bishop DP (1995) Physical and chemical effects of domestic laundering processes. In: Carr CM (ed) Chemistry of the textiles industry. Springer Netherlands, Dordrecht, pp 125-172

Browne MA, Crump P, Niven SJ, Teuten E, Tonkin A, Galloway T, Thompson R (2011) Accumulation of microplastic on shorelines woldwide: sources and sinks. Environ Sci Technol 45:9175-9179. https://doi.org/10.1021/es201811s

Campanale M, Savino et al (2020) A detailed review study on potential effects of microplastics and additives of concern on human health. Int J Environ Res Public Health 17:1212. https://doi.org/10.3390/ ijerph17041212

Carney Almroth BM, Åström L, Roslund S, Petersson H, Johansson M, Persson NK (2018) Quantifying shedding of synthetic fibers from textiles; a source of microplastics released into the environment. Environ Sci Pollut Res 25:1191-1199. https://doi.org/10.1007/ s11356-017-0528-7

Chakraborty JN (2014) Dyeing with indigo. Fundamentals and practices in colouration of textiles. Woodhead Publishing Limited, In, pp $106-120$
Chen H, Qin Y, Huang H, Xu W (2020) A regional difference analysis of microplastic pollution in global freshwater bodies based on a regression model. Water 12:1889. https://doi.org/10.3390/w12071889

Chiweshe A, Crews PC (2000) Influence of household fabric softeners and laundry enzymes on pilling and breaking strength. Text Chem Color Am Dyest Report 32:41-47

Coons D, Dankowski M, Diehl M, Jakobi G, Kuzel P, Sung E, Trabitzsch U (1987) Performance in detergents, cleaning agents and personal care products. In: Falbe J (ed) Surfactants in Consumer Products. Springer, Berlin Heidelberg, Berlin, Heidelberg, pp 197-398

Dave J, Kumar R, Srivastava HC (1987) Studies on modification of polyester fabrics I: Alkaline hydrolysis. J Appl Polym Sci 33:455477. https://doi.org/10.1002/app.1987.070330215

De Falco F, Gentile G, Di Pace E et al (2018a) Quantification of microfibres released during washing of synthetic clothes in real conditions and at lab scale $\star$. Eur Phys J Plus 133:257. https://doi.org/10. 1140/epjp/i2018-12123-x

De Falco F, Gullo MP, Gentile G et al (2018b) Evaluation of microplastic release caused by textile washing processes of synthetic fabrics. Environ Pollut 236:916-925. https://doi.org/10.1016/j.envpol. 2017.10.057

De Falco F, Di Pace E, Cocca M, Avella M (2019) The contribution of washing processes of synthetic clothes to microplastic pollution. Sci Rep 9:6633. https://doi.org/10.1038/s41598-019-43023-x

De Falco F, Cocca M, Avella M, Thompson RC (2020) Microfiber release to water, via laundering, and to air, via everyday use: a comparison between polyester clothing with differing textile parameters. ACS Appl Mater Interfaces 54:3288-3296. https://doi.org/10.1021/ acs.est.9b06892

Dervishi K (2019) The Microplastics Crisis-You are the first responder. http://sitn.hms.harvard.edu/flash/2019/microplastics-crisis/\#: $\sim:$ text=Large plastic debris such as,athleisure clothing) will shed microfibers. Accessed 10 Jul 2020

Duckworth C, Wrennall L (1977) Process advantages and economics of hot mercerizing/flash scouring. J Soc Dye Colour 93:407-412. https://doi.org/10.1111/j.1478-4408.1977.tb03311.x

Gregory MR (2009) Environmental implications of plastic debris in marine settings - entanglement, ingestion, smothering, hangers-on, hitch-hiking\$\$rand alien invasions. Philos Trans R Soc 364:20132025

Gross M (2015) Oceans of plastic waste. Curr Biol 25:R93-R96. https:// doi.org/10.1016/j.cub.2015.01.038

Hartline NL, Bruce NJ, Karba SN, Ruff EO, Sonar SU, Holden PA (2016) Microfiber masses recovered from conventional machine washing of new or aged garments. Environ Sci Technol 50: 11532-11538. https://doi.org/10.1021/acs.est.6b03045

Hernandez E, Nowack B, Mitrano DM (2017) Polyester textiles as a source of microplastics from households: a mechanistic study to understand microfiber release during washing. Environ Sci Technol 51:7036-7046. https://doi.org/10.1021/acs.est.7b01750

Kan CW, Yuen CWM, Cheng CW (2010) Technical study of the effect of $\mathrm{CO} 2$ laser surface engraving on the colour properties of denim fabric. Color Technol 126:365-371. https://doi.org/10.1111/j.14784408.2010.00270.x

Kan CW, Yuen CWM, Wong WY (2011) Optimizing color fading effect of cotton denim fabric by enzyme treatment. J Appl Polym Sci 120: 3596-3603. https://doi.org/10.1002/app.33561

Koelmans AA, Gouin T, Thompson R, Wallace N, Arthur C (2013) Plastics in the marine environment. Environ Toxicol Chem 33:510. https://doi.org/10.1002/etc. 2426

Mcloughlin J, Hayes S (2013) Types of fabric and their joining requirements. Joining Textiles. Elsevier, In, pp 1-44

Napper IE, Thompson RC (2016) Release of synthetic microplastic plastic fibres from domestic washing machines: effects of fabric type and washing conditions. Mar Pollut Bull 112:39-45. https://doi.org/ 10.1016/j.marpolbul.2016.09.025 
Neves D, Sobral P, Lia J, Pereira T (2015) Ingestion of microplastics by commercial fish off the Portuguese coast. Mar Pollut Bull 101:119 126. https://doi.org/10.1016/j.marpolbul.2015.11.008

Nishimura H, Sarko A (1987) Mercerization of cellulose III. Changes in crystallite sizes. J Appl Polym Sci 33:855-866. https://doi.org/10. 1002/app.1987.070330314

Peets P, Leito I, Pelt J, Vahur S (2017) Identification and classification of textile fibres using ATR-FT-IR spectroscopy with chemometric methods. Spectrochim Acta Part A Mol Biomol Spectrosc 173: 175-181. https://doi.org/10.1016/j.saa.2016.09.007

Periyasamy AP (2020) Effects of alkali pretreatment on lyocell woven fabric and its influence on pilling properties. J Text Inst 111:846854. https://doi.org/10.1080/00405000.2019.1665294

Periyasamy AP, Wiener J, Militky J (2017) Life-cycle assessment of denim. Sustainability in Denim, In, pp 83-110

Pirc U, Vidmar M, Mozer A, Kržan A (2016) Emissions of microplastic fibers from microfiber fleece during domestic washing. Environ Sci Pollut Res 23:22206-22211. https://doi.org/10.1007/s11356-0167703-0

Ratnam TV (2010) SITRA Norms for Spinning Mills. South India Textile Research Association. Coimbatore, India

Ritchie H, Roser M (2018) Plastic Pollution. Our world Data, In https:// ourworldindata.org/plastic-pollution. Accessed 2 Mar 2021

Sarkar AK (2015) Dyeing technologies for denim garments. In: Paul RBT-D (ed) Denim: Manufacture. Woodhead Publishing, Finishing and Applications, pp 271-285

Schernewski G, Radtke H, Hauk R, Baresel C, Olshammar M, Osinski R, Oberbeckmann S (2020) Transport and behavior of microplastics emissions from urban sources in the Baltic Sea. Front Environ Sci 8. https://doi.org/10.3389/fenvs.2020.579361

Sillanpää M, Sainio P (2017) Release of polyester and cotton fibers from textiles in machine washings. Environ Sci Pollut Res 24:1931319321. https://doi.org/10.1007/s11356-017-9621-1

Sommer U (2001) How precise labelling can be done? Experience with energy-label verification procedures for washing machines. In: Bertoldi P, Ricci A, de Almeida A (eds) Energy Efficiency in
Household Appliances and Lighting. Springer, Berlin Heidelberg, Berlin, Heidelberg, pp 89-94

Stanton T, Johnson M, Nathanail P, MacNaughtan W, Gomes RL (2019) Freshwater and airborne textile fibre populations are dominated by 'natural', not microplastic, fibres. Sci Total Environ 666:377-389. https://doi.org/10.1016/j.scitotenv.2019.02.278

Technavio (2019) Denim Jeans Market by Distribution Channel and Geography - Forecast and Analysis 2020-2024. https:/cts. businesswire. $\mathrm{com} / \mathrm{ct} / \mathrm{CT}$ ?id=smartlink\&url=https $\% 3 \mathrm{~A} \% 2 \mathrm{~F} \%$ 2 Fwww.technavio.com $\% 2$ Ftalk-to-us $\% 3$ Freport $\%$ 3DIRTNTR40188\%26type\%3Dsample\%26src\%3Dreport\% 26utm_source\%3Dpressrelease\%26utm_medium\%3Dbw\%26utm campaign\%3Dt_auto_rfs_week22\%26utm_content\%3DIRTNTR4. Accessed 2 Mar 2021

Technavio (2020) Global Premium Denim Jeans Market 2020-2024

Thompson RC (2013) Plastics, environment and health. In: Accumulation: The Material Politics of Plastic. pp 150-168

Thompson RC, Olse Y (2004) Lost at sea: where is all the plastic? Science 304:838. https://doi.org/10.1126/science.1094559

Wagner M, Scherer C, Alvarez-Muñoz D, Brennholt N, Bourrain X, Buchinger S, Fries E, Grosbois C, Klasmeier J, Marti T, Rodriguez-Mozaz S, Urbatzka R, Vethaak AD, Winther-Nielsen M, Reifferscheid G (2014) Microplastics in freshwater ecosystems: what we know and what we need to know. Environ Sci Eur 26:1-9. https://doi.org/10.1186/s12302-014-0012-7

Zambrano MC, Pawlak JJ, Daystar J, Ankeny M, Cheng JJ, Venditti RA (2019) Microfibers generated from the laundering of cotton, rayon and polyester based fabrics and their aquatic biodegradation. Mar Pollut Bull 142:394 407. https://doi.org/10.1016/j.marpolbul.2019. 02.062

Zeronian SH, Collins MJ (1989) Surface modification of polyester by alkaline treatments. Text Prog 20:1-26. https://doi.org/10.1080/ 00405168908688948

Publisher's note Springer Nature remains neutral with regard to jurisdictional claims in published maps and institutional affiliations. 